The technical sessions elicited considerable academic interaction between the participants. One technical session was devoted exclusively to industry presentations, an idea conceived in order to bring about closer interaction and stronger links between the industrial sector and MRS-I. As part of this novel endeavor, A. Ramakrishna, president of L \& T-ECC Group, Madras, delivered the lead lecture. The presentations and discussions that followed involved active participation of several prominent representatives of the industrial sector such as Asian Electronics, Mumbai; Magnetic Solutions, United
States; Optilase, Madras; SICO, Madras; and Steuerung, Hyderabad.

Two satellite symposia were also offered, one by Baldev Raj, director of Metallurgy and materials Science Group, IGCAR, Kalpakkam and S. Ramaprabhu, Department of Physics, IIT-Madras, entitled, "Alternate Energy Materials." This symposium focused on a wide spectrum of topics including hydrogen storage materials, energy options vis-a-vis material resources, solar photovoltaics, fuel cells, thermoelectric sources, processing properties-performance of materials, and advanced energy management systems. IIT-Madras was the venue of the second satellite symposium, coordinated by $\mathrm{O}$. Prabhakar of the Department of Metallurgy, IIT-Madras, entitled, "New Materials and Processing Technologies." This too covered a wide spectrum of topics such as microporous and mesoporous solids, nanomaterials, rapidly solidified materials, biomaterials, advanced engineering materials, superplasticity and dynamic forming, directional solidification, surface engineering, selfpropagating high-temperature synthesis, and intelligent processing materials.

S.V. SUBRAMANYAM

GENERAL SECRETARY, MRS-I

\section{IUMRS-ICA 98 to be Held in India in October}

The 5th International Union of Materials Research Societies International Conference on Advanced Materials (IUMRSICAM '99), organized by the Materials Research Society of China (C-MRS), will be held in Beijing, China at the Beijing International Convention Center (BICC) June 13-18, 1999. As the last IUMRS-ICAM in this century, the organizers are designing the conference as a forum to give a forward look to materials science while striding into a new century.

The 35 symposia and three forums are as follows:

A Nanostructured Materials

B High- $\mathrm{T}_{\mathrm{c}}$ Superconductors

C Fullerenes and Related Materials

D Intermetallic Compounds and Bulk Metallic Glasses

E Diamond Films and Related Materials

F Thin Films and Multilayers: Science and Applications

$G$ Intelligent Materials and Integrated Systems

H Functional Polymers

I Hard Magnetic Materials

J Advanced Information Recording Materials \& Processing

K Materials, Devices, and Applications for Advanced Optical Communication

L Science \& Technology of Artificial Crystals

M Si-Based Materials and Devices

$N$ Compound Semiconductor Materials

O Low-Dimensional Structures and Quantum Devices

P Display Materials

Q Radiation Detectors for Imaging in Industry and Medicine

R Materials Research Inspired by Biological Systems

S Biomedical Materials

$\mathrm{T}$ Materials for Energy Conversion

U Ecomaterials

V Rare Earths and Applications

W Material Synthesis and Modification by Energetic Beams
$X \quad$ Surface Engineering

$Y$ Science and Engineering of Solidification

Z Materials Research and Thermal Physics in Extreme Cases

AA Forward Look to Materials Science While Striding into a New Century

BB Advanced Processing of Materials

CC Light Metals

DD Advanced Ceramics

EE Advanced Polymeric Structural Materials

FF Advance in Composite Materials

GG Advanced Materials Characterization and Imaging

HHMaterials Design and Modeling

II Advances in Porous Materials

FA The Role of Advanced Materials in Social and Economic Sustainable Development

FB Global Networks on Materials Research and Development

FC Materials Education Language.

English is the official language of the conference. The abstract deadline is February 1, 1999. Conference registration fees are $\$ 395$ before March 31, 1999 and $\$ 445$ after March 31, 1999 which includes a volume of symposium abstracts, coffee breaks, reception, entertainment, banquet, and technical visit. The fees for students is $\$ 200$ before March 31, 1999 and \$250 after March 31, 1999.

For more information, contact Secretariat, IUMRS-ICAM-1999, C-MRS Office, 7 Baishiqiao Road, Beijing, 100081, CHINA; email: lhd-dms@tsinghua. edu.cn; hanyf@ public.east.cn.net; or cmrssec@public. bta.cn.net. Fax and Phone: Prof. L.I. Hengde, Tsinghua University, Beijing, +86-1062771160 (fax), +86-10-627857(phone); Dr. Han Yafang, Beijing Institute of Aeronautical Materials, +86-10-62466925 or +86-1062456212 (fax), $+86-10-62451667$ or 62452103 (phone); and C-MRS Office, +86-10-68428640 (fax) $+86-10-68428640$ (phone). The IUMRSICAM '99 website is http:/ / www.chimeb. edu.cn/meeting/e_mrs99.htm.
The 5th International Union of Materials Research Societies International Conference in Asia (IUMRS-ICA), organized by Materials Research Society of India (MRS-I) and IUMRS, will be held in Bangalore, India, at the Indian Institute of Science, Jawaharlal Nehru Entre for Advanced Scientific Research, October 13-16, 1998. This conference is held annually to share ideas and achievements in the area of materials science and technology. The earlier conferences in this series were organized by MRS-China (1993), MRS-Taiwan (1994), MRS-Korea (1995), and MRS-Japan (1997).

The scope of the conference includes current developments in the experimental and theoretical studies of materials. The presentations and discussions are expected to help in the fundamental understanding of materials and identify materials processes for technology. English will be the official language of the conference.

Registration fees are Rs. 1500 for participants from India, Rs. 750 for students from India, $\$ 300$ for participants outside of India, and $\$ 150$ for students outside of India. The fee includes participation in the sessions, conference lunches and dinners, banquets, and a copy of the proceedings of the conference.

For more information, contact Prof. S.V. Subramanyam, General Secretary, MRSIndia, IUMRS-ICA 98 Secretariat, Department of Physics, Indian Institute of Science, Bangalore, 560 012, India; phone 0091-803340416/3092525; 0091-80-3484307 (res.); fax 0091-80-3340416/3341683.

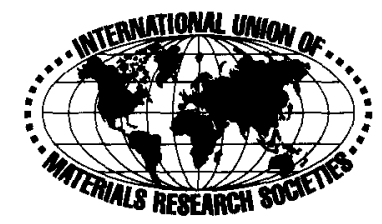

